\title{
Transmission of Cyclocoelum mutabile (Digenea) to snails: the influence of temperature on the egg and miracidium
}

\author{
Christopher W. McKindsey ${ }^{1}$ and J. Daniel McLaughlin \\ Department of Biology, Concordia University, 1455 de Maisonneuve Boulevard West, Montréal, QC H3G 1M8, Canada \\ Received March 16, 1994 \\ Accepted July 20, 1994
}

\begin{abstract}
McKindsey, C.W., and McLaughuin, J.D. 1994. Transmission of Cyclocoelum mutabile (Digenea) to snails: the influence of temperature on the egg and miracidium. Can. J. Zool. 72: 1745-1751.

This study examined the survival and hatching dynamics of eggs of the digenean Cyclocoelum mutabile and the survivorship and infectivity of the miracidia under different temperature regimes. Hatching did not occur at or below $12^{\circ} \mathrm{C}$. Hatching success was similar at 14,16 , and $20^{\circ} \mathrm{C}(69-73 \%)$. Two peaks in hatching were seen. Most eggs hatched within $12 \mathrm{~h}$ following immersion in water; a smaller hatching peak occurred about $24 \mathrm{~h}$ later. Storing eggs at $12^{\circ} \mathrm{C}$ for up to 4 weeks prior to raising the incubation temperature to $14^{\circ} \mathrm{C}$ had no effect on hatching success. However, hatching success was dependent on the source of the eggs. Between 62 and $71 \%$ of the eggs from faeces and $90-98 \%$ of the eggs dissected from flukes hatched under the same protocol. Miracidia hatching from eggs stored for $0-7$ weeks at $7^{\circ} \mathrm{C}$ prior to hatching at $14^{\circ} \mathrm{C}$ did not differ in their infectivity to snails $(75-86 \%)$. The survivorship of miracidia was higher at lower temperatures and when they were obtained from eggs dissected from the fluke. The longer survival and prolonged infectivity of miracidia at lower temperatures produced the highest transmission efficiency at $14^{\circ} \mathrm{C}$. These results are discussed in relation to the seasonal transmission and ecology of the fluke.
\end{abstract}

McKindsey, C.W., et McLaughlin, J.D. 1994. Transmission of Cyclocoelum mutabile (Digenea) to snails: the influence of temperature on the egg and miracidium. Can. J. Zool. $72: 1745-1751$.

On trouvera ici les résultats d'une étude de la survie et de l'éclosion des oeufs de la douve Cyclocoelum mutabile (Digenea) ainsi que de l'influence de la température sur la survie et le caractère infectieux des miracidies. L'éclosion n'a pas lieu à des températures égales ou inférieures à $12^{\circ} \mathrm{C}$. Le succès de l'éclosion est le même à 14,16 et $20^{\circ} \mathrm{C}(69-73 \%)$. Il se produit deux modes au cours de l'Eclosion. La plupart des oeufs éclosent moins de 12 heures après l'immersion dans l'eau; il se produit une autre période d'éclosion moins importante $24 \mathrm{~h}$ plus tard. L'incubation des oeufs à $12^{\circ} \mathrm{C}$ pour une période allant jusqu'à 4 semaines avant l'augmentation de température à $14^{\circ} \mathrm{C}$ n'affecte pas le succès de l'éclosion. Cependant, le succès de l'éclosion dépend de l'origine des oeufs. Au cours de cette étude, $62-71 \%$ des oeufs provenant des fèces et $90-98 \%$ des oeufs prélevés chez les douves par dissection ont éclos dans les mêmes conditions. Les miracidies obtenues d'oeufs gardés pendant $0-7$ semaines à $7^{\circ} \mathrm{C}$ avant l'éclosion à $14^{\circ} \mathrm{C}$ avaient le même pouvoir infectieux pour des gastropodes $(75-86 \%)$. La survie des miracidies est plus élevée lorsqu'elles proviennent d'oeufs obtenus par dissection et lorsque la température est basse. C'est à des taux de survie élevés et lorsque la durée de la période infectieuse est longue à des températures basses que l'efficacité de transmission à $14^{\circ} \mathrm{C}$ est le plus élevée. Ces résultats sont examinés en fonction de la transmission saisonnière et de l'écologie de la douve.

[Traduit par la Rédaction]

\section{Introduction}

Cyclocoelum mutabile (Zeder, 1800) is a large digenean that infects the air sacs of coots (Fulica spp.). American coots ( $F$. americana) arrive on their breeding grounds in western Canada with patent infections each spring. Recruitment of new infections is extremely rare in the spring and the parasite virtually disappears from adult coots in mid to late June (Colbo 1965; McLaughlin 1986). Evidently, metacercariae either do not survive the winter in the snail population or, if they do, are unavailable to coots. It appears, therefore, that new infections must be established in local snail populations each spring. Several species are susceptible to infection (McKindsey 1993) and may be involved in transmission to coots, which begins in mid-July (McLaughlin 1986).

The life cycle of $C$. mutabile is well adapted for rapid production of metacercariae in snails. Embryonated eggs passed from the coot hatch soon after contact with water. The miracidium contains a young redia that is injected into the snail. This is the only redial generation, and cercariae, produced in 3 weeks under optimal conditions, encyst in situ (McLaughlin 1976). Snails exposed in May or June could,

\footnotetext{
'Present address: GIROQ, Département de Bilologie, Université Laval, Québec, QC G1K 7P4, Canada.
}

therefore, produce the metacercariae necessary to generate infections appearing in young coots in mid to late July.

Temperature may affect both the survivorship and infectivity of transmission stages and is one of the most important factors influencing the transmission dynamics of digeneans (Evans 1985). Thus, the influence of temperature on the survival and infectivity of eggs and miracidia of $C$. mutabile throughout the spring may have a profound effect on the establishment of infections in snails and, ultimately, on the transmission back to coots.

This study examines the effect of temperature on the survival and hatching dynamics of $C$. mutabile eggs and on the survivorship and infectivity of the miracidia as part of a larger project on the ecology of this fluke.

\section{Materials and methods}

Eggs used in the following experiments were obtained from the faeces of laboratory-infected coots following techniques outlined in McKindsey and McLaughlin (1993) (referred to hereafter as passed eggs) or dissected directly from flukes obtained at necropsy (dissected eggs). Unless otherwise stated, all experiments were carried out in incubators at $T \pm 1^{\circ} \mathrm{C}$ under constant incandescent illumination. All manipulations during the harvesting of the eggs were performed at the same temperature as the experiment. 
The original objective of these experiments was to examine the effect of a range of temperatures likely to be encountered by eggs shed in the spring $\left(4,8,12,16\right.$, and $\left.20^{\circ} \mathrm{C}\right)$. However, eggs held at or below $12^{\circ} \mathrm{C}$ did not hatch and the experiments were modified to include trials at 14,16 , and $20^{\circ} \mathrm{C}$, with $14^{\circ} \mathrm{C}$ considered the hatching threshold.

\section{Temperature-dependent hatching dynamics}

Passed eggs were used in this experiment. In each of two trials conducted at each temperature, single eggs were placed in separate wells ( $3 \mathrm{~mL}$ water per well) of eight 24 -well tissue culture plates. Timing of the experiment $(t=0)$ began when the faeces were diluted to obtain the eggs. Eggs were examined every hour for the first $48 \mathrm{~h}$ and then every $12 \mathrm{~h}$ for the following 5 days. An egg was considered hatched when the miracidium was free of the egg. The effects considered in this experiment were the overall hatching success and the distribution of the hatching times of eggs incubated at the different temperatures.

\section{Egg viability following prolonged cold storage}

Passed and dissected eggs collected at $12^{\circ} \mathrm{C}$ were placed in 16 (passed eggs) or 18 (dissected eggs) 24-well tissue culture plates, as described above. These were stored for up to 4 weeks at $12^{\circ} \mathrm{C}$. At intervals of $12,24,48$, and $96 \mathrm{~h}$ and $1,2,3$, and 4 weeks (dissected eggs only), two plates were selected at random and warmed to $14^{\circ} \mathrm{C}$. The plates were monitored daily for 1 week and eggs not hatching by day 7 were considered dead. Two control plates were maintained at $12^{\circ} \mathrm{C}$ and examined under the same schedule as the experimental plates. Three separate trials were performed using passed eggs; a single trial was performed with dissected eggs. Hatching success was the only effect considered.

\section{Miracidial infectivity: effect of egg age}

Dissected eggs were placed in five Drosophila vials screened with $37-\mu \mathrm{m}$ mesh at each end (Lee et al. 1992), and placed in an aerated aquarium at $7^{\circ} \mathrm{C}$. At intervals of $0,1,3,5$, and 7 weeks, one randomly selected container was removed and the eggs were rinsed into a petri dish and left to hatch at room temperature $\left(20 \pm 2{ }^{\circ} \mathrm{C}\right)$. Three newly hatched miracidia (less than half an hour old) were added to each well of a 24-well tissue culture plate containing a single Gyraulus parvus (shell diameter 3-5 mm). The G. parvus used in all experiments were wild-caught, and maintained in plastic aquaria on a diet of boiled romaine lettuce in the laboratory for a minimum of 1 week prior to use. Each was examined just prior to use for the presence of sporocysts, rediae, and (or) cercarial shedding by observation under a dissecting microscope. The snails were exposed for $2 \mathrm{~h}$, then removed and placed in plastic aquaria. They were dissected at 34 weeks post infection (p.i.) and the number of rediae in each snail was recorded. The 1:1 ratio of rediae to miracidia permitted a direct estimation of infection success.

\section{Miracidial survivorship}

This experiment used both passed and dissected eggs. Young miracidia ( $<30$ min old) hatching from eggs incubated at 14,16 , or $20^{\circ} \mathrm{C}$ were pipetted to individual wells of 9-spot depression plates and maintained at the corresponding temperature. Their activity was monitored every hour until they died. A miracidium was considered dead when it was motionless and failed to respond to mechanical stimulation. Two trials consisting of six plates each were performed using miracidia hatching from each egg source. Survivorship of miracidia at different temperatures and from the different egg sources was compared.

\section{Miracidial infectivity: effect of miracidial age}

Dissected eggs were incubated at 14,16 , and $20^{\circ} \mathrm{C}$ until they hatched. Three newly hatched miracidia were placed in each well of a series of 24-well tissue culture plates and returned to the corresponding incubator. At set intervals $(0,1,2,3, \ldots 12,16$, and $20 \mathrm{~h}$ ), a single snail ( $G$. parvus, size class $3.0-5.0 \mathrm{~mm}$ ) was added to each well of one plate and the plate returned to the incubator. Snails were exposed for $2 \mathrm{~h}$, then transferred to plastic cups contain- ing $250 \mathrm{~mL}$ of culture water. The snails were held at the experimental temperature for an additional $24 \mathrm{~h}$ and then kept at $20 \pm 2^{\circ} \mathrm{C}$ for the duration of the experiment. Snails were dissected 3-4 weeks p.i. and the number of rediae found was recorded. Three trials were performed at each temperature.

\section{Statistical analysis}

Statistical procedures were carried out following Sokal and Rohlf (1981) and SPSS Inc. (1990) and using either SPSS (SPSS Inc. 1990) or SYSTAT (Wilkinson 1990). In all cases, results were accepted as significant at $P<0.05$. A Bonferroni-adjusted critical value $(P \leq$ $0.05 / g$, where $g$ is the number of comparisons made) was used whenever multiple comparisons were performed (Wilkinson 1990).

\section{Results}

\section{Temperature-dependent hatching dynamics}

The results of the two trials done at each temperature were pooled prior to analysis. There was no significant difference in the mean hatching success of passed eggs incubated under the three temperature regimes $(69.3,73.4$, and $70.6 \%$ at 14 , 16 , and $20^{\circ} \mathrm{C}$, respectively) (Wilks $G$ test, $G=1.71, P=$ 0.426 ). Although the distribution of hatching times differed between temperatures (Kolmogorov-Smirnov test, $Z=3.791$, 3.711 , and 3.326 for pairwise tests of $14 \times 16,14 \times 20$, and $16 \times 20^{\circ} \mathrm{C} ; P<0.0005$ for each pairwise test), the median hatch time did not (median test, $\chi^{2}=5.04, P=0.080$ ) and a general trend was seen at each temperature (Fig. 1). No hatching occurred within the first $2 \mathrm{~h}$, and most eggs hatched within the first $12 \mathrm{~h}$. A second, smaller peak occurred at $22-30 \mathrm{~h}$ incubation. Few eggs hatched at other times, and none did so beyond 6 days incubation.

\section{Egg viability following prolonged cold storage}

The hatching success of eggs stored at $12^{\circ} \mathrm{C}$ and then raised to $14^{\circ} \mathrm{C}$ is shown in Fig. 2 . As the hatching success of passed eggs did not differ significantly between trials (heterogeneity $G$ test, $G=2.59,0.25<P<0.50$ ), the results were pooled. There was no significant difference in hatching success of passed eggs stored at $12^{\circ} \mathrm{C}$ for up to 3 weeks when raised to $14^{\circ} \mathrm{C}(G=4.22, P=0.647)$. The hatching success of eggs stored at $12^{\circ} \mathrm{C}$ was similar to that of fresh eggs incubated at $14^{\circ} \mathrm{C}(G=0.76, P=0.382)$.

Similarly, no significant differences in the hatching success of dissected eggs stored for between $12 \mathrm{~h}$ and 4 weeks at $12^{\circ} \mathrm{C}$ prior to warming to $14^{\circ} \mathrm{C}$ were seen $(G=6.65, P=0.466)$.

None of the 48 dissected eggs from control plates and only 5 of 144 control eggs from coot faeces (one each at 12, 24, and $48 \mathrm{~h}$ and 1 and 2 weeks) hatched.

A $G$ test of partial independence revealed highly significant differences in the hatching success of eggs derived from the two sources $(G=115.93, P<0.0005)$. The mean hatching success of dissected eggs stored at $12^{\circ} \mathrm{C}$ and then hatched at $14^{\circ} \mathrm{C}$ was $93.8 \%$, fully $25 \%$ higher than that seen in eggs isolated from coot faeces and stored for the same period $(68.3 \%)$.

\section{Miracidial infectivity: effect of egg age}

The infection success of miracidia hatching from eggs stored for up to 7 weeks at $7^{\circ} \mathrm{C}$ prior to being raised to $14^{\circ} \mathrm{C}$ did not differ significantly $(G=5.53, P=0.237)$. The results are shown in Fig. 3.

\section{Miracidial survival}

The widely used Anderson and Whitfield (1975) models that describe the age-dependent survivorship $\left(P_{t}\right)$ and instantane- 


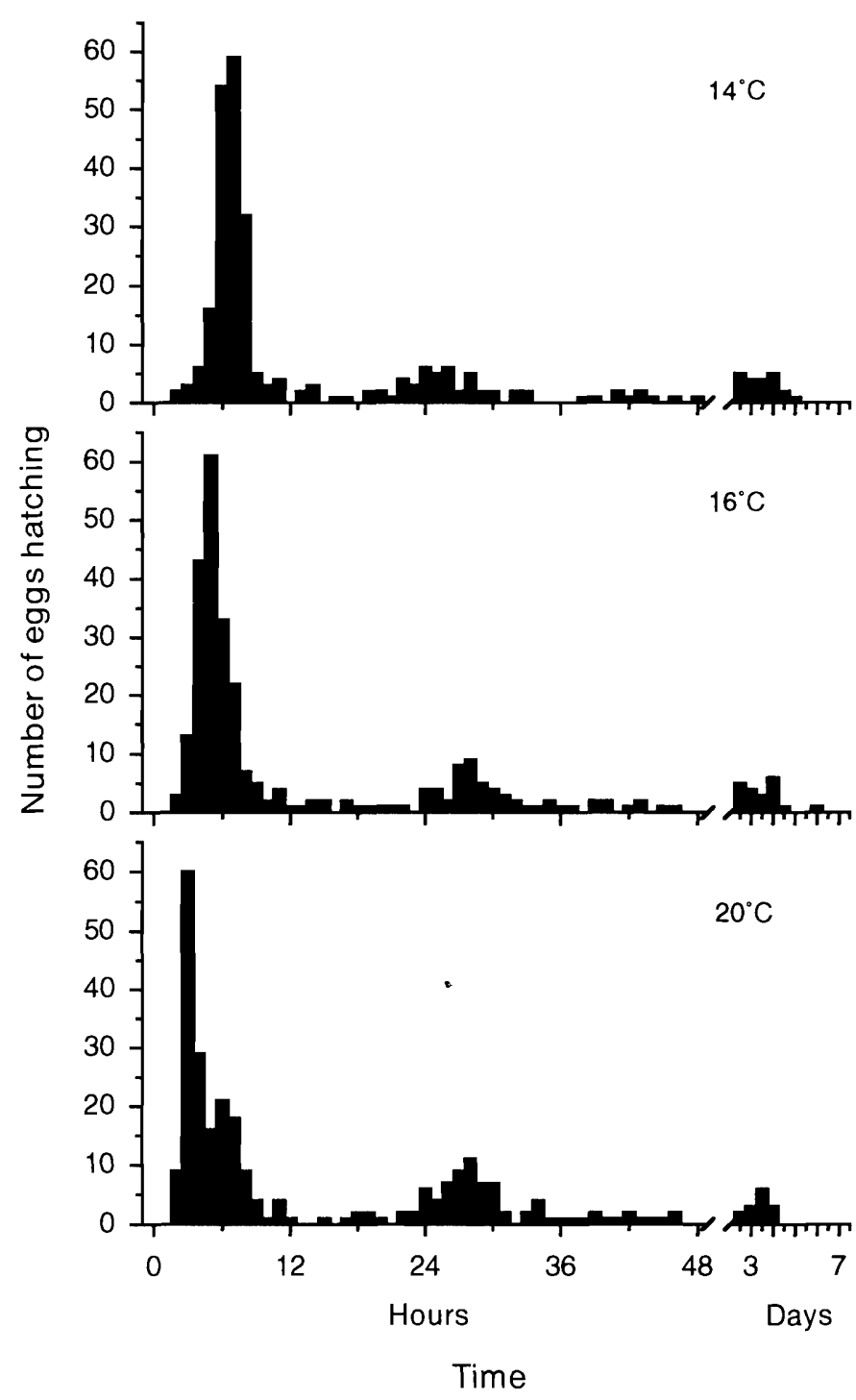

FIG. 1. Hatching distribution of Cyclocoelum mutabile eggs incubated at three temperatures.

ous death rates $\left(\mu_{t}\right)$ of larval parasitic stages, in this case the miracidia, as follows:

[1] $P_{t}=\exp \left\{\frac{a}{b}[1-\exp (b t)]\right\}$

and

[2] $\mu_{t}=a \exp (b t)$

provided a good approximation of the experimental data (Fig. 4, Table 1). Here, the constants $a$ and $b$ represent the instantaneous death rate of the miracidia at hatching $(t=0)$ and the magnitude of the increase in mortality as the miracidia age, respectively.

The survivorship data were normalized by combining the trials from each egg source at each temperature and discarding a total of 8 outlying values (all attempts to normalize the data without combining the trials failed). Analysis by ANOVA showed that miracidial survival was inversely related to incubation temperature $(F=1090.55, P<0.0005)$, miracidia hatching from dissected eggs survived longer than those from

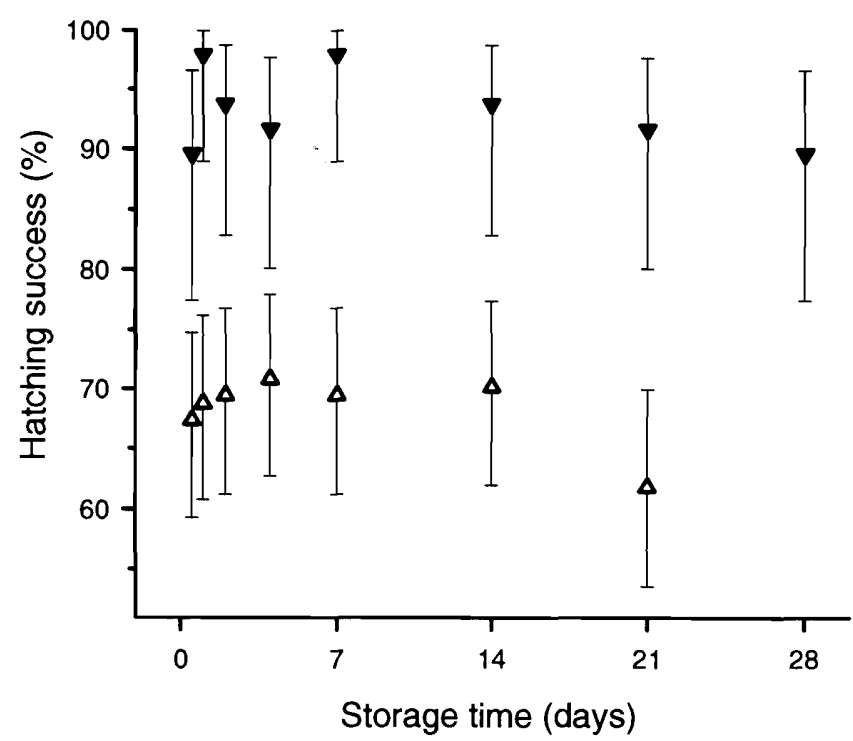

Fig. 2. Hatching success (mean $\pm 95 \%$ confidence limits) of Cyclocoelum mutabile eggs stored for varying lengths of time at $12^{\circ} \mathrm{C}$ prior to being raised to $14^{\circ} \mathrm{C}$. $\triangle$, eggs from coot faeces; $\nabla$, eggs dissected from worms.

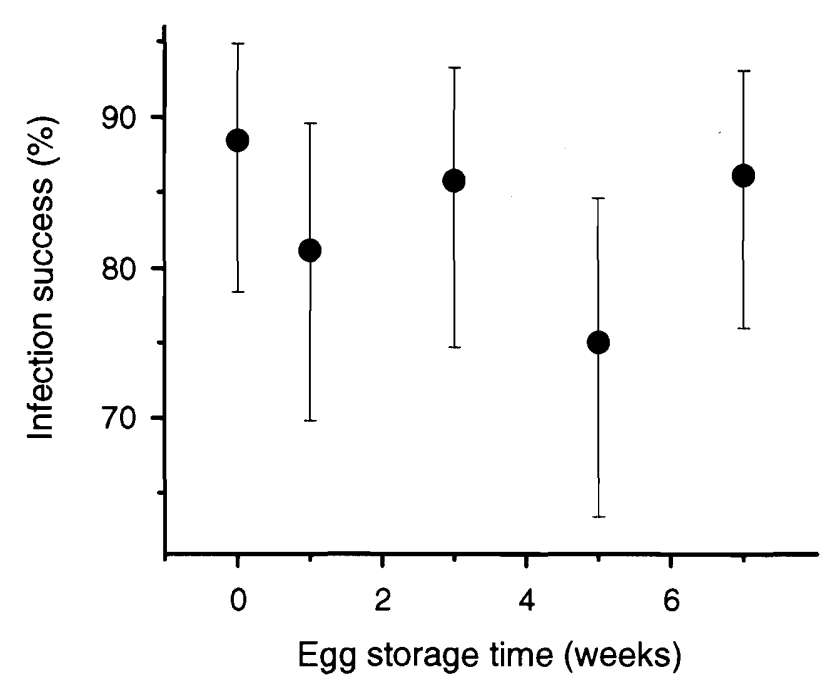

FIG. 3. Infectivity (means $\pm 95 \%$ confidence limits) of Cyclocoelum mutabile miracidia, hatching from eggs stored for varying lengths of time at $7^{\circ} \mathrm{C}$, to 3- to 5-mm Gyraulus parvus at $20^{\circ} \mathrm{C}$.

passed eggs $(F=206.39, P<0.0005)$, and there was no interaction between these two effects $(F=1.57, P=0.208)$.

Miracidial infectivity: effect of aging

The proportion of miracidia at different ages that were infective to snails at 14,16 , and $20^{\circ} \mathrm{C}$ is shown in Fig. 5. Stepwise logistic and linear regression were used to determine the relative significance of miracidial age, incubation temperature, and the interaction between the two on the infectivity of the miracidia. Although both analyses yielded similar results, only those from the linear model are presented here, as they are simpler to interpret (Tabachnick and Fidell 1989). Judging by the magnitude of the semipartial correlations given for each variable in Table 2 , it may be seen that infectivity of miracidia was best explained by the interaction between age and temperature. However, both miracidial age and, to a lesser extent, 


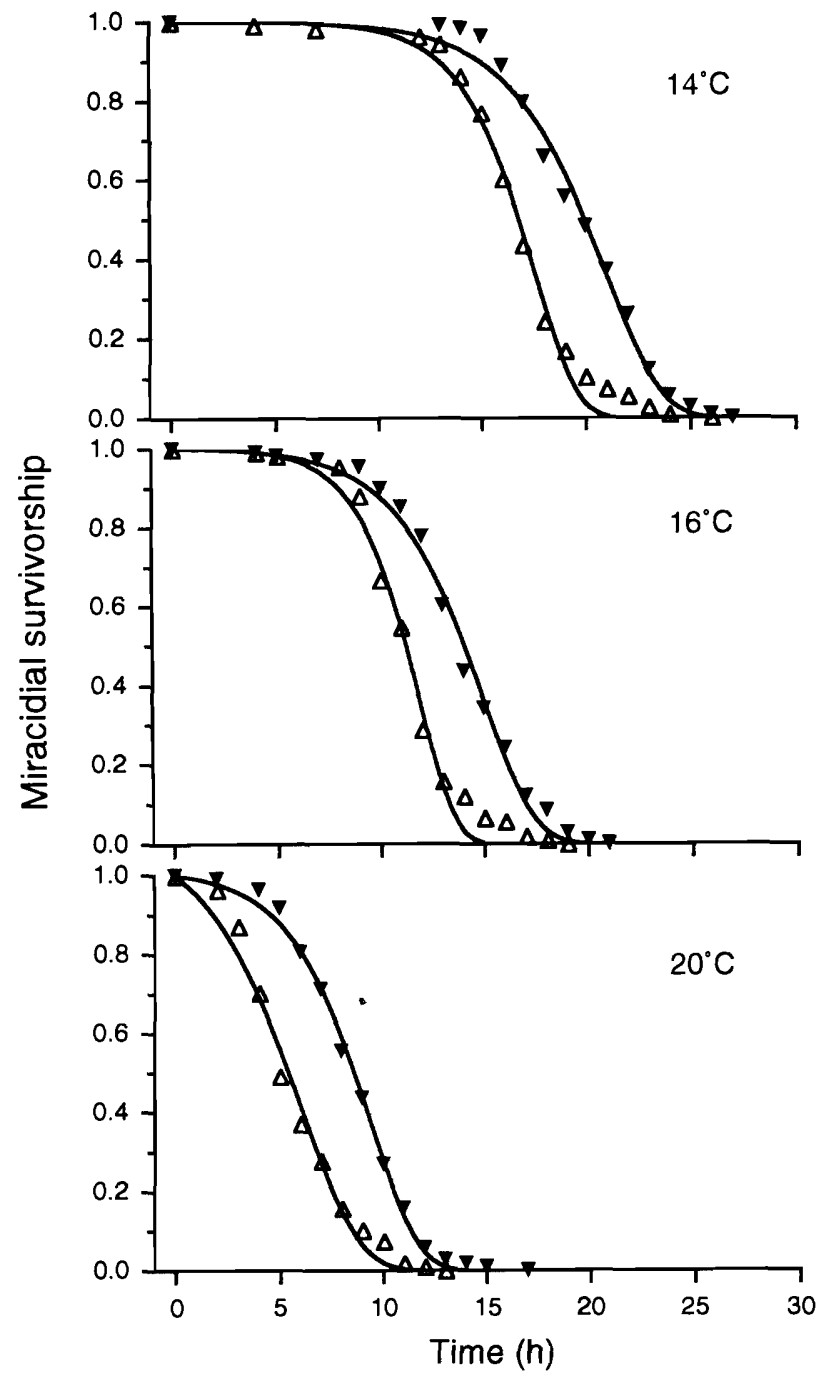

FIG. 4. Survivorship of Cyclocoelum mutabile miracidia hatching from eggs obtained from two sources at three temperatures. Data points represent the mean proportion of miracidia alive at time $t$, estimated from the two trials. $\triangle$, eggs from coot faeces; $\nabla$, eggs dissected from worms; - $\longrightarrow$, best fit curves from the model described by eq. 1 . See Table 1 for parameter estimates.

temperature also explained significant amounts of the variance in the model (Table 2). Partitioning of the results showed that infectivity did not differ between temperatures at hatching or during the first $2 \mathrm{~h}$ (Wilks' $G$ test, $0.60<P<0.90$ ). Infectivity of miracidia incubated at $20^{\circ} \mathrm{C}$ began to decline after $4 \mathrm{~h}$ $(G=34.65, P<0.0005)$, whereas the infectivity at both 14 and $16^{\circ} \mathrm{C}$ began to decline after only $2 \mathrm{~h}(G=11.83, P=$ 0.008 , and $G=25.38, P<0.0005$, respectively). Once initiated, the decline in infectivity was greatest at $20^{\circ} \mathrm{C}$ and lowest at $14^{\circ} \mathrm{C}$ (ANCOVA, $F=13.85, P<0.0005$ ).

The age-dependent instantaneous rates of infection of the miracidia, $\beta_{t}$, were calculated (Anderson 1978) from the redial recovery data:

$$
\beta_{t}=\frac{-\ln \left(1-\frac{R}{M_{0}}\right)}{E}
$$

where $R$ is the number of rediae recovered per snail, $M_{0}$ the number of miracidia present in the well at $t=0$, and $E$ the
TABLE 1. Constant values and fit of the Anderson and Whitfield (1975) survival model $P_{t}=\exp \left\{\frac{a}{b}[1-\exp (b t)]\right\}$ for Cyclocoelum mutabile miracidia derived from eggs dissected from worms or passed with coot faeces at three temperatures

\begin{tabular}{|c|c|c|c|c|c|c|}
\hline \multirow{2}{*}{$\begin{array}{l}\text { Egg } \\
\text { source }\end{array}$} & \multirow{2}{*}{$\begin{array}{c}\text { Temp. } \\
\left({ }^{\circ} \mathrm{C}\right)\end{array}$} & \multicolumn{2}{|c|}{$a$} & \multicolumn{2}{|c|}{$b$} & \multirow[b]{2}{*}{$r^{2}$} \\
\hline & & Mean & SE & Mean & SE & \\
\hline Dissected & 14 & 0.00009 & 0.00004 & 0.491 & 0.033 & 0.993 \\
\hline Dissected & 16 & 0.00061 & 0.00032 & 0.578 & 0.053 & 0.990 \\
\hline Dissected & 20 & 0.04161 & 0.00803 & 0.356 & 0.045 & 0.986 \\
\hline Passed & 14 & 0.00015 & 0.00006 & 0.373 & 0.022 & 0.992 \\
\hline Passed & 16 & 0.00096 & 0.00025 & 0.405 & 0.022 & 0.994 \\
\hline Passed & 20 & 0.00722 & 0.00093 & 0.436 & 0.018 & 0.997 \\
\hline
\end{tabular}

TABLE 2. Influence of miracidial age and environmental temperature on the transmission of Cyclocoelum mutabile to snails

\begin{tabular}{lrrr}
\hline \hline Variable & $\begin{array}{c}\text { Coefficient } \\
\text { value }\end{array}$ & \multicolumn{1}{c}{$T^{*}$} & $\begin{array}{l}\text { Semipartial } \\
\text { correlation }\end{array}$ \\
\hline Interaction & -0.0075 & -17.226 & \\
Temperature & 0.0182 & 5.901 & -0.142 \\
Age (h) & 0.0571 & 8.522 & 0.049 \\
Constant & 0.5138 & 10.147 & 0.071 \\
\hline
\end{tabular}

NoTE: The value, significance, and unique contribution of each of the coefficients to the total variance are explained by the following model: miracidial infectivity $=$ constant + temperature + age + interaction, where the interaction effect is simply temperature $\times$ age. Fit of the model: $r^{2}=0.343$.

${ }^{*} P<0.0005$ for all variables.

TABLE 3. Constant values and fit of the quadratic model $\beta_{t}=$ $x-y t^{z}$ describing the instantaneous rates of infection of 3- to 5-mm Gyraulus parvus with Cyclocoelum mutabile miracidia at three temperatures

\begin{tabular}{|c|c|c|c|c|c|c|c|}
\hline \multirow{2}{*}{$\begin{array}{l}\text { Temp. } \\
\left({ }^{\circ} \mathrm{C}\right)\end{array}$} & \multicolumn{2}{|c|}{$x$} & \multicolumn{2}{|c|}{$y$} & \multicolumn{2}{|c|}{$z$} & \multirow[b]{2}{*}{$r^{2}$} \\
\hline & Mean & SE & Mean & SE & Mean & SE & \\
\hline 14 & 0.775 & 0.051 & 0.130 & 0.038 & 0.655 & 0.088 & 0.957 \\
\hline 16 & 0.755 & 0.064 & 0.148 & 0.052 & 0.641 & 0.114 & 0.936 \\
\hline 20 & 0.765 & 0.096 & 0.050 & 0.047 & 1.253 & 0.398 & 0.888 \\
\hline
\end{tabular}

exposure time. Although a number of authors have proposed a variety of modeis to describe these types of data (e.g., Anderson et al. 1977; Evans and Gordon 1983), a simple quadratic model of the form

[4] $\beta_{l}=x-y t^{2}$

where $x, y$, and $z$ are constants estimated by nonlinear regression, was found to provide the best, although strictly empirical, description of the data (see Table 3).

Division of the area under each infection curve by the infective life-span of the miracidia provides a single summary statistic of infectivity, $\bar{\beta}$, the mean instantaneous rate of infection of the miracidia over the infective life-span of the miracidia (Evans 1985). The calculated values of $\bar{\beta}$ are given in Table 4.

May and Anderson (1978) calculate the transmission effi- 


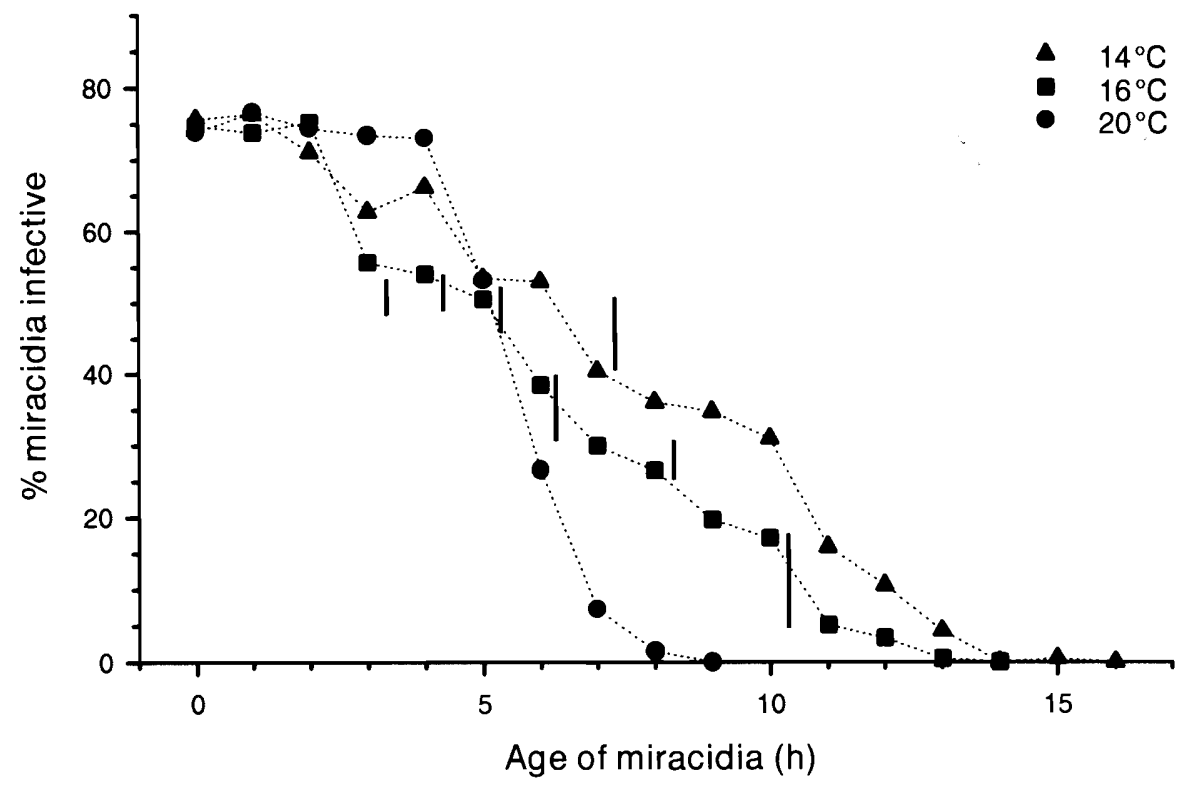

FIg. 5. Age-dependent infectivity of Cyclocoelum mutabile miracidia to 3- to 5-mm Gyraulus parvus at three different temperatures. Vertical lines show nonsignificant differences in infectivity of miracidia between temperatures at a given time $(G$ test, $P<0.05)$.

TABLE 4. Influence of temperature on the transmission parameters of Cyclocoelum mutabile miracidia (see the text for details)

\begin{tabular}{lccccr}
\hline \hline $\begin{array}{c}\text { Egg } \\
\text { source }\end{array}$ & $\begin{array}{c}\text { Temp. } \\
\left({ }^{\circ} \mathrm{C}\right)\end{array}$ & $I_{\max }$ & $\bar{\beta}$ & $\bar{\mu}$ & $\bar{\beta} / \bar{\mu}$ \\
\hline Dissected & 14 & 24 & 0.284 & 0.010 & 28.728 \\
Dissected & 16 & 20 & 0.262 & 0.049 & 5.381 \\
Dissected & 20 & 14 & 0.408 & 0.092 & 4.446 \\
Passed & 14 & 26 & & & \\
Passed & 16 & 20 & & & \\
Passed & 20 & 16 & & & \\
\hline
\end{tabular}

ciency of parasite infective stages, $H_{0}$, by the ratio of the death rate of the infective stages $(\bar{\mu})$ to the rate at which the infective stages invade the host $(\bar{\beta})$. These may be calculated as

[5] $\bar{\mu}=\frac{1}{I_{\max }} \int_{t=0}^{I_{\max }} \bar{\mu}_{t}$

and

[6] $\bar{\beta}=\frac{1}{I_{\max }} \int_{t=0}^{I_{\max }} \bar{\beta}_{t}$

where $I_{\max }$ is the maximal observed infective life-span of a miracidium. $H_{\mathrm{o}}$ varies inversely with the proportion of infective stages that establish in the host, and Evans (1985) suggests that the inverse of this value $\left(1 / H_{0}=\bar{\beta} / \bar{\mu}\right)$ yields a more intuitive measure of transmission efficiency. These values are presented in Table 4. Although the mean instantaneous rate of infection was highest at $20^{\circ} \mathrm{C}$, the high rate of miracidial mortality at this temperature (see Table 4) acts to produce the lowest transmission efficiency. Conversely, the transmission efficiency was highest at $14^{\circ} \mathrm{C}$, despite the comparatively low mean instantaneous rate of infection due to the greater miracidial survivorship at this temperature.

\section{Discussion}

The eggs of the majority of digeneans are unembryonated when shed and require a period of development before hatching. The development of intramolluscan stages also requires a period of time before cercariae and, ultimately, metacercariae are produced. Embryonation and development rates are influenced by temperature and, accordingly, the only immediate source of infection to birds arriving on the breeding grounds in early spring are overwintered stages.

Coots arrive on their breeding grounds in western Canada with patent infections of $C$. mutabile in mid-April (Colbo 1965; McLaughlin 1986), shortly after spring breakup and when water temperatures are low. As the eggs are fully embryonated, there is no temperature-mediated developmental delay. However, a temperature threshold exists below which eggs do not hatch. Our results suggest that eggs, passed by coots from the time they arrive, accumulate for several weeks in wetlands before bottom temperatures reach $14^{\circ} \mathrm{C}$, then hatch en masse. As storage for up to 4 and 7 weeks at subthreshold temperatures had no effect on the hatching success of eggs or the infectivity of miracidia, respectively, most of the eggs accumulating in wetlands over this period would release infective miracidia.

Pulmonate snails in temperate regions, many species of which are susceptible to infection by $C$. mutabile (McKindsey 1993), typically begin oviposition once water temperatures reach about $7-11^{\circ} \mathrm{C}$ (Duncan 1975; McMahon 1983). Surface temperatures increase much sooner than bottom temperatures (Wetzel 1983), and new cohorts of young snails would be available by the time bottom temperature reaches $14^{\circ} \mathrm{C}$ and the fluke eggs begin to hatch. Infections resulting from these miracidia, in addition to those from eggs deposited throughout the rest of the spring, would produce the metacercarial pools in the snail populations that are the source of infections seen in coots later in the summer.

The eggs of $C$. mutabile are already embryonated when shed, and hatching is initiated within hours, yet they showed a bimodal and extended hatching distribution. Factors con- 
trolling the second, lesser surge are unknown; however, environmental factors, including daylight cycle, are known to influence the hatching of trematode eggs (Hawking 1975). There are both theoretical and empirical reasons to expect animals living in unpredictable environments to have phenotypically variable offspring (see Shostak and Dick 1989). Even limited variation in the timing of egg hatching would increase the temporal dispersion of the miracidia in the environment, thereby increasing the chances of at least some encountering snail hosts.

Miracidial survival was not only a function of temperature, as expected, but was also dependent on the source of the eggs. Weina (1986) also observed source-dependent effects on the eggs of Paragonimus kellicotti from cats. Eggs from the lung embryonated 10 days sooner than those from faeces, but no explanation for this observation was offered. Eggs dissected from the uteri of flukes obtained at necropsy are younger than those obtained from the faeces. In the case of $C$. mutabile, the length of time required for eggs to leave the hosts once they are laid is unknown. Prolonged retention in the air sacs at the host's body temperature might affect the level of energy reserves available once eggs have been passed from the host, possibly resulting in the lower survival of miracidia seen here. Alternatively, passage through the gut or the procedure used to separate the eggs from the faeces may somehow affect the eggs or miracidia.

The observation that miracidia do not remain infective over their entire life-span is in agreement with results reported for other species (e.g., Chernin 1968; Christensen et al. 1976; Anderson 1978; Prah and James 1977; Evans and Gordon 1983; Anderson et al. 1982; Smith and Grenfell 1984; Evans 1985; Waadu 1991). Although miracidia hatching at all three temperatures were initially equally infective, the infectivity of those hatching at $20^{\circ} \mathrm{C}$ remained maximal longer and declined more rapidly than the infectivity of those hatching at lower temperatures. Although miracidia hatching at lower temperatures maintained maximal infectivity for shorter periods, infectivity levels declined much more slowly with decreasing temperature.

Miracidial invasiveness is related to activity (Anderson 1978), which in turn is correlated positively with environmental temperature and negatively with age (Wilson and Denison 1970; Prah and James 1977). Thus, miracidia hatching at higher temperatures may start and remain above a level of activity required for successful penetration longer than miracidia incubated at lower temperatures. However, once below this threshold, the decline in infectivity would be most severe at the higher temperatures. In contrast, miracidia at lower temperatures may exhibit lower levels of activity (but still above the threshold), with many remaining above this threshold for a longer period. A shorter period of maximal infectivity, coupled with a prolonged period during which the infectivity remains high, would be advantageous in early spring, when snails are generally less abundant and more widely dispersed. Alternatively, a cohort of miracidia hatching at $20^{\circ} \mathrm{C}$ would display maximal infectivity for a comparatively short time, a strategy that would be particularly advantageous in the summer, when the density of many snail species in temperate wetlands is greatest (McKindsey 1993).

Temperature had a significant effect on the transmission efficiency of $C$. mutabile under experimental conditions. Other studies on miracidia (Anderson et al. 1982) and cercariae (Evans 1985) have demonstrated that high instantaneous rates of transmission observed at higher temperatures are offset by lower survival rates. This results in a wide temperature range over which transmission efficiencies are high. These reports are in contrast with results obtained in this study, where maximal transmission efficiency occurred at laboratory temperatures just above the hatching threshold. Anderson (1978) and Wilson and Taylor (1978) have shown that the net rate of infection is proportional to the density of miracidia and snail hosts present in a system. In addition, Anderson et al. (1982) have demonstrated that transmission efficiencies may only be expressed maximally under high host densities. Thus, although transmission efficiency (as determined from data on the miracidia) is highest near threshold temperature, the availability and density of the snail populations, which may be influenced in a variety of ways in different wetlands, could have a significant effect on the actual transmission efficiency of miracidia early in the year.

Taken together, these results suggest that $C$. mutabile is well adapted for transmission to snails in the spring. Eggs deposited by coots in early spring would accumulate until the bottom temperature reached $14^{\circ} \mathrm{C}$. These would then hatch en masse, most of the miracidia being infective. Prolonged survival and infectivity at low temperatures would allow the miracidia to search for widely dispersed snails before infectivity declined greatly. Eggs deposited later in the spring, when temperatures are higher, would also contribute to the development of the infective pool in the snail community, as higher snail densities would offset lower transmission efficiencies. The reduction in the number of intramolluscan stages in the life cycle would result in the development of a new metacercarial generation by midsummer, when coots begin to acquire new infections.

\section{Acknowledgements}

We thank the many people at the Delta Waterfowl and Wetlands Research Station who assisted in this study and without whom this work could not have been completed. The Canadian Wildlife Service generously supplied the necessary permits required for the collection of both coots and coot eggs. Financial support to C.W. McKindsey for this research was provided by the North American Wildlife Foundation through a graduate research grant and through a demonstratorship funded by the Department of Biology, Concordia University. Thanks also go to Dr. P.J. Albert (Department of Biology, Concordia University) for assistance with the figures and to Dr. A.W. Shostak (Department of Zoology, the University of Alberta) for comments on an earlier draft of this paper.

Anderson, R.M. 1978. Population dynamics of snail infection by miracidia. Parasitology, 77: 201-224.

Anderson, R.M., and Whitfield, P.J. 1975. Survival characteristics of the free-living cercarial population of the ectoparasite Transversotrema patialensis (Soparker, 1924). Parasitology, 70: $295-$ 310.

Anderson, R.M., Whitfield, P.J., and Mills, C.A. 1977. An experimental study of the population dynamics of an ectoparasitic digenean, Transversotrema patialensis: the cercarial and adult stages. J. Anim. Ecol. 46: 555-580.

Anderson, R.M., Mercer, J.G., Wilson, R.A., and Carter, N.P. 1982. Transmission of Schistosoma mansoni from man to snail: experimental studies of miracidial survival and infectivity in relation to larval age, water temperature, host size and hosts age. Parasitology, 85: 339-360.

Chernin, E. 1968. Interference with the capacity of Schistosoma 
mansoni miracidia to infect the molluscan host. J. Parasitol. 54: $509-516$.

Christensen, N.Ø., Nansen, P., and Frandsen, F. 1976. The influence of temperature on the infectivity of Fasciola hepatica miracidia to Lymnaea truncatula. J. Parasitol. 62: 698-701.

Colbo, M.H. 1965. Taxonomy and ecology of the helminths of the American coot in Alberta. M.Sc. thesis, the University of Alberta, Edmonton.

Duncan, C.J. 1975. Reproduction. In Pulmonates. Vol. 1. Functional anatomy and physiology. Edited by V. Fretter and J. Peake. Academic Press, London. pp. 309-365.

Evans, N.A. 1985. The influence of environmental temperature upon the transmission of Echinostoma liei (Digenea: Echinostomatidae). Parasitology, 90: 269-275.

Evans, N.A., and Gordon, D.M. 1983. Experimental studies on the transmission dynamics of the cercariae of Echinoparyphium recurvatum (Digenea: Echinostomatidae). Parasitology, 87: 167-174.

Hawking, F. 1975. Circadian and other rhythms of parasites. In Advances in parasitology. Vol. 13. Edited by B. Dawes. Academic Press, London. pp. 123-182.

Lee, J., Pilgrim, W., McLaughlin, J.D., and Burt, M.D.B. 1992. Effects of temperature on the oncospheres of the cestode Microsomacanthus hopkinsi and its implication for their overwinter survival. Can. J. Zool. 70: 935-940.

May, R.M., and Anderson, R.M. 1978. Regulation and stability of host-parasite population interactions. J. Anim. Ecol. 47: 249267.

McKindsey, C.W. 1993. Lab and field studies on the establishment of Cyclocoelum mutabile (Zeder, 1800) (Digenea) infections in snail communities. M.Sc. thesis, 'Concordia University, Montréal.

McKindsey, C.W., and McLaughlin, J.D. 1993. The viability of Sphaeridiotrema pseudoglobulus (Digenea) eggs following cold water storage as a possible overwintering strategy. Parasitology, 107: $441-447$.

McLaughlin, J.D. 1976. Experimental studies on the life cycle of Cyclocoelum mutabile (Zeder) (Trematoda: Cyclocoelidae). Can. J. Zool. 54: 48-54.

McLaughlin, J.D. 1986. The biology of Cyclocoelum mutabile
(Trematoda) infections in American coots. Proc. Helminthol. Soc. Wash. 53: $177-181$.

McMahon, R.F. 1983. Physiological ecology of freshwater pulmonates. In The Mollusca. Vol. 6, Ecology. Edited by W.D. Russell-Hunter. Academic Press, Orlando, Fla. pp. 359-430.

Prah, S.K., and James, C. 1977. The influence of physical factors on the survival and infectivity of miracidia of Schistosoma mansoni and $S$. haematobium. I. Effect of temperature and ultra-violet light. J. Helminthol. 51: 73-85.

Shostak, A.W., and Dick, T.A. 1989. Variability in timing of egg hatch of Triaenophorus crassus Forel (Cestoda: Pseudophyllidea) as a mechanism increasing temporal dispersion of coracidia. Can. J. Zool. 67: $1462-1470$.

Smith, G., and Grenfell, B.T. 1984. The influence of water temperature and $\mathrm{pH}$ on the survival of Fasciola hepatica miracidia. Parasitology, 88: $97-104$.

Sokal, R.R., and Rohlf, F.J. 1981. Biometry: The principles and practice of statistics in biological research. 2 nd ed. W.H. Freeman and Co., San Francisco.

SPSS Inc. 1990. SPSS reference guide. SPSS Inc., Chicago.

Tabachnick, B.G., and Fidell, L.S. 1989. Using multivariate statistics. 2nd ed. Harper and Row, Publishers, New York.

Waadu, G.D.B. 1991. Diplostomum spathaceum (Rud. 1819): effect of miracidial age and lifespan on miracidial infectivity. J. Helminthol. 65: $28-30$.

Weina, P.J. 1986. Factors in developmental delay of Paragonimus kellicotti miracidia. J. Parasitol. 72: 779.

Wetzel, R.G. 1983. Limnology. 2nd ed. Saunders College Publishing, New York.

Wilkinson, L. 1990. SYSTAT: the system for statistics. SYSTAT, Inc., Evanston, Ill.

Wilson, R.A., and Denison, J. 1970. Studies on the activity of the miracidium of the common liver fluke, Fasciola hepatica. Comp. Biochem. Physiol. 32: 301-313.

Wilson, R.A., and Taylor, S.L. 1978. The effect of variations in host and parasite density on the level of parasitization of Lymnaea truncatula by Fasciola hepatica. Parasitology, 76: $91-98$. 